BMJ Open Diabetes Research \& Care

\title{
Effect of vitamin $\mathrm{D}_{3}$ supplementation on glycated hemoglobin (HbA1c), fructosamine, serum lipids, and body mass index: a randomized, double- blinded, placebo-controlled trial among healthy immigrants living in Norway
}

\author{
Ahmed A Madar, ${ }^{1}$ Kirsten V Knutsen, ${ }^{2}$ Lars C Stene, ${ }^{3}$ Mette Brekke, ${ }^{2}$ \\ Haakon E Meyer, ${ }^{1,3}$ Per Lagerløv ${ }^{2}$
}

To cite: Madar AA, Knutsen KV, Stene LC, et al. Effect of vitamin $D_{3}$ supplementation on glycated hemoglobin $(\mathrm{HbA1C})$, fructosamine, serum lipids, and body mass index: a randomized, double-blinded placebo-controlled trial among healthy immigrants living in Norway. BMJ Open Diabetes Research and Care 2014:2:e000026

doi:10.1136/bmjdrc-2014000026

- Additional material is available. To view please visit the journal online (http://dx. doi.org/10.1136/bmjdrc2014-000026).

Received 20 February 2014 Revised 26 May 2014 Accepted 4 August 2014

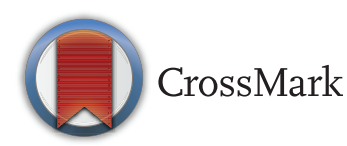

For numbered affiliations see end of article.

Correspondence to Dr Ahmed A Madar; a.a.madar@medisin.uio.no

\section{ABSTRACT}

Objective: Despite the suggested role of vitamin $D$ in the prevention of diabetes and cardiovascular disease or its risk factors, the evidence is not consistent and there is a paucity of randomized controlled trials in this field. We aimed to investigate the effect of 16-week daily vitamin $D_{3}$ supplementation on glycated hemoglobin (HbA1C), fructosamine, body mass index (BMI), and serum lipids.

Design: Double-blind, randomized, placebo-controlled trial.

Setting: Immigrant community centers in 0slo, Norway.

Participants: 251 healthy adults aged $18-50$ years with a non-Western immigrant background. All participants performed the baseline test and 215 $(86 \%)$ returned to the follow-up test.

Intervention: 16 weeks of daily oral supplementation with either $10 \mu \mathrm{g}$ vitamin $D_{3}, 25 \mu \mathrm{g}$ vitamin $D_{3}$, or placebo.

Main outcome measures: Difference in absolute change during the 16-week intervention between the intervention groups combined (10 or $25 \mu \mathrm{g}$ of vitamin $\mathrm{D}_{3}$ /day) and placebo, in $\mathrm{HbA1c}$, fructosamine, serum lipids (total cholesterol, low-density lipoprotein cholesterol, high-density lipoprotein cholesterol, and triglycerides), and BMI.

Results: A total of $215(86 \%)$ participants completed the study. Serum 25 -hydroxyvitamin $D$ increased from $29 \mathrm{nmol} / \mathrm{L}$ at baseline to $49 \mathrm{nmol} / \mathrm{L}$ after intervention, with little change in the placebo group. However, there was no difference in change of $\mathrm{HbA1c}$ between those receiving vitamin $D_{3}$ compared with placebo (mean difference: $0.01 \%(95 \% \mathrm{Cl}-0.04$ to $0.06, \mathrm{p}=0.7))$. Neither did the vitamin $D_{3}$ supplementation have any effect on the other end points: fructosamine, serum lipids, and BMI.

Conclusions: 16 -week vitamin $D_{3}$ supplementation to healthy immigrants from South Asia, the Middle East, or Africa and now living in Norway with low vitamin $D$ status did not improve $\mathrm{HbA1c}$, fructosamine, lipid

\section{Key messages}

Immigrants are at risk both for viatmin D deficiency, overwieght and diabetes type-2.

- Effective and specific preventive means for vitamin $D$ deficiency, overweight and risk of diabetes in immigrant population should be explored.

More studies are needed to study the long-term health consequences of the low vitamin D status of immigrants.

profiles, or BMI. An updated meta-analysis of similar published trials showed that our results were generally consistent with those of other studies.

Trial registration number: NCT01263288.

\section{INTRODUCTION}

Vitamin D deficiency is widespread among immigrants from non-Western countries in Europe and elsewhere. ${ }^{1-4}$ Classical outcomes of severe vitamin $\mathrm{D}$ deficiency are rickets in children and osteomalacia in adults. Low vitamin D status is also a risk factor for low bone density and osteoporotic fractures. Furthermore, during the past decades, the vitamin $\mathrm{D}$ receptor has been found in many tissues and new actions of vitamin $\mathrm{D}$ have been described. ${ }^{5}$

Immigrants, particularly those from South Asia and the Middle East, are at high risk of type 2 diabetes ${ }^{6-8}$ and have a high prevalence of cardiovascular risk factors such as unfavorable serum lipids. ${ }^{9}{ }^{10}$ Several epidemiological studies have suggested increased risks of diabetes or impaired glucose metabolism and cardiovascular diseases among persons with low vitamin D status. ${ }^{11-14}$ 
Despite the suggested role of vitamin D in the prevention of diabetes and cardiovascular disease, the evidence is not consistent and there is a paucity of randomized controlled trials (RCTs) assessing the effect of vitamin D supplementation on these outcomes. In particular, few studies have been carried out on immigrants living in developed countries, who are at increased risk of both hypovitaminosis D and diabetes. ${ }^{6}$ To study whether vitamin D supplementation has an effect on glucose metabolism, serum lipids and body mass index (BMI) in healthy adults with an immigrant background in Norway, we have carried out a randomized, double-blinded, controlled trial.

Results from the primary end point have previously been reported. ${ }^{15}$ We present results from predefined additional end points. The aim was to test whether 16 weeks of daily vitamin D3 supplementation (10 or $25 \mu \mathrm{g}$ /day vs placebo) would reduce glycated hemoglobin (HbA1c), fructosamine, and BMI and improve serum lipids.

\section{RESEARCH DESIGN AND METHODS}

Study design and participants

The study was conducted between January and June 2011 and further details of the study method have been described elsewhere. ${ }^{15}$ Participants were healthy men and women, aged 18-50 years, who were born or had parents born in the Middle East, Africa, and South Asia. They were recruited through 11 different community centers in Oslo and surrounding areas (at latitude $60^{\circ} \mathrm{N}$ ). They were excluded if they regularly used vitamin D-containing supplements, were receiving treatment for vitamin D deficiency, were pregnant or breastfeeding, used medication for hypoglycemia or hyperlipidemia, malabsorption, used medication interfering with the vitamin D metabolism (such as thiazides, antiepileptic drugs, prednisolone, or hormone replacement therapy), had kidney disease, cancer, tuberculosis, sarcoidosis, osteoporosis, or a recent fracture, or used strong painkillers prescribed by a physician such as Paralgin forte and Aporex. The same data collection team visited all the centers and performed the baseline and follow-up data collection. Interpreters were used when necessary, but the majority of the study participants were able to communicate in the Norwegian language.

\section{RANDOMIZATION AND INTERVENTION}

Those who fulfilled the eligibility criteria were randomly assigned to one of three equally sized intervention groups receiving one tablet per day containing $25 \mu \mathrm{g}$ vitamin $\mathrm{D}_{3}, 10 \mu \mathrm{g}$ vitamin $\mathrm{D}_{3}$, or placebo. The tablets were similar in color, size, and packing. Each study participant was given a box of 120 tablets (a 16-week use corresponds to 112 tablets) at baseline with a selfadministered compliance form. The tablets were manufactured by Bioplus Life Sciences Pvt Ltd, DMA (Bangalore, India), certified for Good Manufacturing
Practice, and the ingredients met the requirements of British Pharmacopé. If the study participants had forgotten to take one tablet a day, they were asked to take two tablets the following day. The participants were followed up with a short text message twice a week to remind them to take the tablets. They were advised to maintain their usual dietary pattern during the 16-week trial period and contact the study staff by telephone if they had any inquiries.

\section{MAIN OUTCOME VARIABLES}

The study outcomes were difference in absolute change during the 16-week intervention between the intervention groups combined ( 10 or $25 \mu \mathrm{g}$ of vitamin $\mathrm{D}_{3} /$ day) and placebo, in HbAlc, fructosamine, serum lipids (total cholesterol, low-density lipoprotein (LDL) cholesterol, high-density lipoprotein (HDL) cholesterol, and triglycerides), and BMI. HbAlc is correlated with the average glucose level over the preceding $2-3$ months, ${ }^{16}$ and it can be measured in non-fasting blood samples. Fructosamine reflects the average blood glucose level over the preceding 2-3 weeks, and the assay is not influenced by hemoglobinopathies or iron deficiency anemia that may influence HbA1c measurements. ${ }^{17}$

\section{BLOOD SAMIPLING AND LABORATORY ASSAYS}

Non-fasting venous blood was drawn at baseline and at the follow-up after 16 weeks. Blood for serum was collected in serum-separator gel tubes and centrifuged after $30 \mathrm{~min}$ to $2 \mathrm{~h}$, and blood for plasma was collected in EDTA tubes and centrifuged within $30 \mathrm{~min}$ at room temperature at the study site. Serum and plasma were separated and frozen in several aliquots at $-20^{\circ} \mathrm{C}$ the same day and within $1-2$ weeks frozen at $-80^{\circ} \mathrm{C}$ until they were analyzed. After the completion of the study, all serum samples from baseline and follow-up were analyzed in one batch at the Fürst Medical Laboratory (http://www.furst.no), which is accredited by the International Organization for Standardization and is part of the vitamin D External Quality Assessment Scheme (DEQAS).

Serum 25-hydroxyvitamin D (s-25(OH)D) was measured using high-pressure liquid chromatography tandem mass spectrometry, with Waters Acquity UPLC and Waters triple quadrupole mass spectrometer instruments. Both $25(\mathrm{OH}) \mathrm{D}_{2}$ and $25(\mathrm{OH}) \mathrm{D}_{3}$ levels were measured and the sum of the two was used for analysis (termed $25(\mathrm{OH}) \mathrm{D}$, even though $25(\mathrm{OH}) \mathrm{D}_{2}$ was negligible). The within-batch coefficient of variation for s-25 $(\mathrm{OH}) \mathrm{D}_{3}$ was $4.8 \%$ within high concentrations and $7.2 \%$ within low concentrations.

HbAlc was analyzed on a cation exchange column chromatograph using an automated high-pressure liquid chromatography instrument (HLC-723 G7, Tosoh Corporation, Tokyo, Japan). The reference upper normal for HbAlc is $<6.1 \%$. The total coefficient of variation was $2 \%$ at HbA1c levels around $6.1 \%$. 
Fructosamine was measured using a colorimetric enzymatic method (ADVIA 2400 Siemens). The interassay coefficient of variation $(\mathrm{CV})$ was $2.3 \%$ and reference upper normal was $285 \mu \mathrm{mol} / \mathrm{L}$.

Total cholesterol, LDL-cholesterol, HDL-cholesterol, and triglycerides were measured using an enzymatic method (ADVIA 2400 Siemens). The interassay coefficients of variation were $1.3 \%$ (total cholesterol), $1.6 \%$ (LDL-cholesterol), $1.8 \%$ (HDL-cholesterol), and $3.8 \%$ (triglycerides).

Body weight was measured with a Bosogramm 3000 Scale (loading capacity $150 \mathrm{~kg}$ ) to the nearest $100 \mathrm{~g}$ with participants in indoor clothing without shoes. Height was measured to the nearest centimeter with a rigid meter standard. The same devices were used both at baseline and at follow-up. The participants completed an interviewer-administered questionnaire at baseline and follow-up. Information about age, ethnicity, education, and duration of residence in Norway was collected at baseline.

\section{RANDOMI ALLOCATION}

We chose a computer-generated block randomization to ensure a good balance of the number in each group during the trial and randomly varied the block size between 3 and 6 .

\section{BLINDING}

Group allocation was unknown to participants, research staff, investigators, and data collectors. Data analyses were also blinded. The tablet boxes were numbered according to the randomization list by an external pharmacy (the Hospital Pharmacy at Oslo University Hospital). The group allocation list was stored at this pharmacy with a copy in a sealed envelope. Each participant was consecutively numbered and received a prepackaged tablet box with the corresponding number. The analyses of the primary outcome measures and the evaluation of the physical performance tests were performed before the randomization list was opened. At the end, the results of s-25(OH)D and plasma parathyroid hormone (PTH) analyses at follow-up were unmasked.

\section{REGISTRATION}

The study was authorized as a clinical trial by the Norwegian Medicine Agency. It has been registered at EudraCT (2010-021114-36). The clinical trial was conducted according to the principles of the Declaration of Helsinki and in accordance with national laws (ClinicalTrials.gov identifier NCT01263288).

\section{STATISTICAL ANALYSES}

The sample size was planned for an effect of the intervention on muscle strength and power. This was the main end point of the trial, and these results are presented elsewhere. ${ }^{15}$ This suggested that we should include 210 participants, and under the assumption of expected dropout rates of $15-20 \%$ we aimed to recruit at least 250 participants. We also calculated that this sample size would provide $80 \%$ power to detect a difference of 0.5 (\% points) in HbAlc between the intervention and control groups, a difference we considered clinically relevant. ${ }^{18}$

Statistical analysis of the data was performed using the IBM SPSS statistical software (V.19.0; SPSS Inc, Chicago, Illinois, USA). For each of the outcome variables, we calculated the difference in change from baseline to follow-up between the combined intervention groups (10 or $25 \mu \mathrm{g} /$ day) and the placebo group. This was analyzed using linear regression analysis, where the effect on each outcome variable was adjusted for the respective baseline concentration. Similar analyses were also performed to compare $25 \mu \mathrm{g} /$ day to placebo and $10 \mu \mathrm{g} /$ day to placebo. p Values $<0.05$ were considered statistically significant.

Subgroup analyses by baseline values of end point measures, gender, and intervention dose were also performed.

All participants provided written consent. The participants were instructed that they would receive a notification by letter, if the analysis of their blood sample later showed deviant values with a recommendation to contact their regular general practitioners.

\section{Role of the funding source}

Nycomed, which supplied study tablets and other sponsors, had no role in the study design, data collection, data analysis, data interpretation, or writing of the report.

\section{RESULTS}

\section{Participants}

We screened 301 persons for inclusion in the study, of whom 251 met the inclusion criteria and agreed to participate. They were randomly assigned to one of the three intervention groups. After 16 weeks, 215 (86\%) study participants returned to the follow-up visit, including one who declined to take the blood sample (figure 1).

\section{Baseline characteristics}

No substantial between-group differences in baseline values were noted (table 1 ). The mean baseline s-25 $(\mathrm{OH}) \mathrm{D}$ concentration for the whole study population was $28.9(\mathrm{SD} 17.6) \mathrm{nmol} / \mathrm{L}$ and $90 \%$ had s-25(OH)D $<50 \mathrm{nmol} / \mathrm{L}$ while $53 \%$ had $\mathrm{s}-25(\mathrm{OH}) \mathrm{D}<25 \mathrm{nmol} / \mathrm{L}$. Around $38 \%$ had HbA1c levels equal to or above $5.7 \%$. The baseline correlation between HbAlc and serum fructosamine was $0.47(\mathrm{p}<0.001)$. There was no significant difference in baseline variables in the participants who did not complete the study $(n=37)$ compared with those completed the study $(n=214)$. 


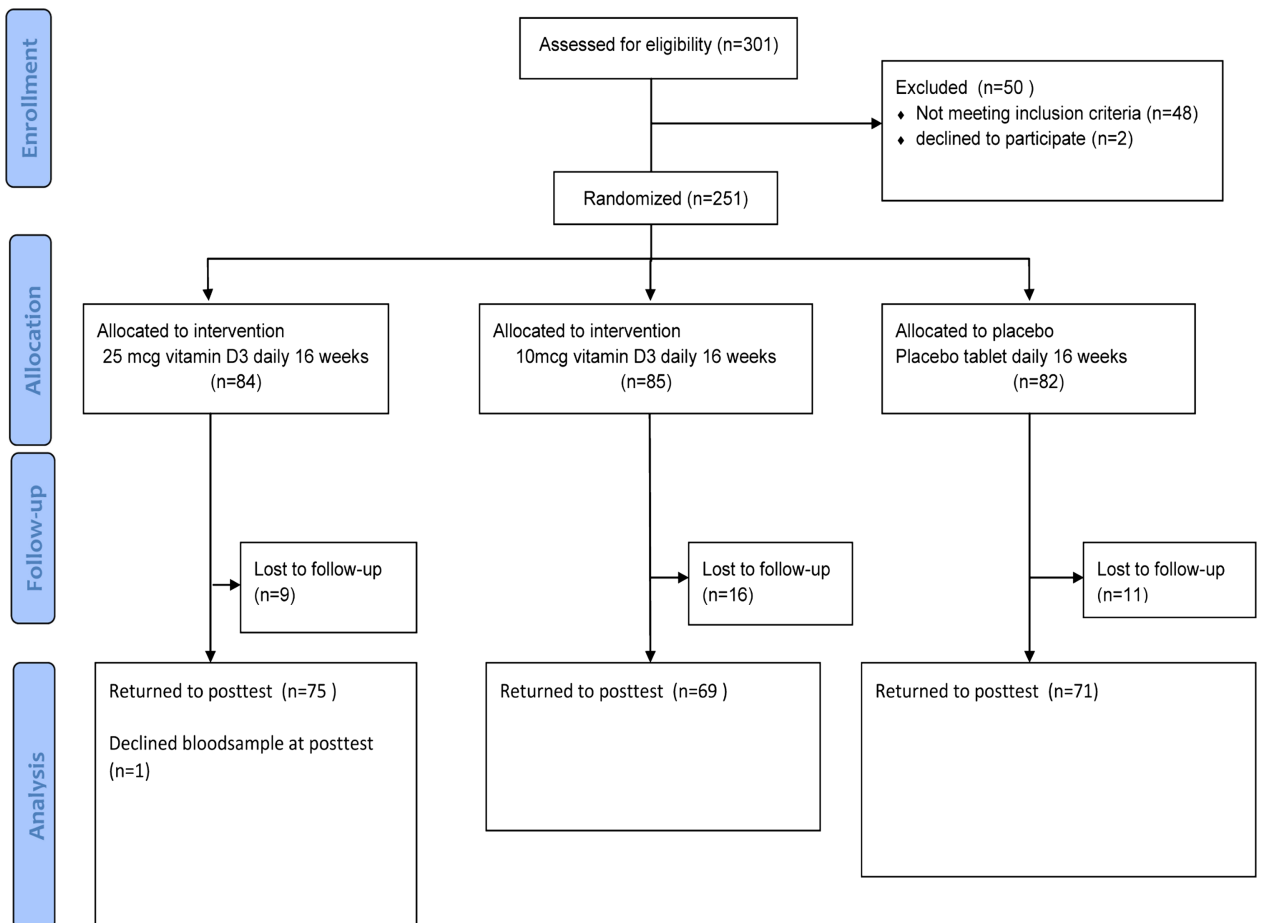

Figure 1 Flow chart of recruitment, randomization, and follow-up.

Table 1 Baseline characteristics for study participants by supplementation group*

\begin{tabular}{|c|c|c|c|}
\hline Characteristics & $\begin{array}{l}\text { Vitamin D }(25 \mu \mathrm{g}) \\
\mathrm{N}=84\end{array}$ & $\begin{array}{l}\text { Vitamin } D(10 \mu g) \\
N=85\end{array}$ & $\begin{array}{l}\text { Placebo } \\
\mathrm{N}=82\end{array}$ \\
\hline Age (years) & $36(8.2)$ & $37(7.6)$ & $39(7.6)$ \\
\hline \multicolumn{4}{|l|}{$\operatorname{Sex}(n, \%)$} \\
\hline Male & $26(31)$ & $24(28)$ & $19(23)$ \\
\hline Female & $58(69)$ & $61(72)$ & $63(77)$ \\
\hline \multicolumn{4}{|l|}{ Regional origin (n, \%) } \\
\hline South Asia & $31(37)$ & $31(36)$ & $33(40)$ \\
\hline Middle East and North Africa & $15(18)$ & $9(11)$ & $12(15)$ \\
\hline Sub-Saharan Africa & $38(45)$ & $45(53)$ & $37(45)$ \\
\hline Years lived in Norway (mean, range) & $13.3(1-29)$ & $13.2(1-35)$ & $13.6(2-33)$ \\
\hline \multicolumn{4}{|l|}{ Level of education, years $(n, \%)$} \\
\hline$\leq 10$ & $34(40)$ & $36(42)$ & $33(40)$ \\
\hline $11-13$ & $30(36)$ & $31(37)$ & $34(42)$ \\
\hline$\geq 14$ & $20(24)$ & $18(21)$ & $15(18)$ \\
\hline S-25(OH)D (nmol/L) & $26.9(16.5)$ & $29.8(20.6)$ & $30.1(18.9)$ \\
\hline $\mathrm{HbA1c}(\%) \dagger$ & $5.6(0.65)$ & $5.6(0.51)$ & $5.6(0.43)$ \\
\hline Fructosamine $(\mu \mathrm{mol} / \mathrm{L})$ & $251(50.5)$ & $248(35.9)$ & $245(30.1)$ \\
\hline Total cholesterol (mmol/L) & $4.8(0.79)$ & $4.9(0.82)$ & $4.9(0.90)$ \\
\hline HDL-cholesterol (mmol/L) & $1.4(0.31)$ & $1.4(0.31)$ & $1.4(0.32)$ \\
\hline LDL-cholesterol (mmol/L) & $3.3(0.85)$ & $3.3(0.88)$ & $3.4(0.86)$ \\
\hline Triglycerides $(\mathrm{mmol} / \mathrm{L})$ & $1.6(0.91)$ & $1.5(1.2)$ & $1.6(1.13)$ \\
\hline BMI $\left(\mathrm{kg} / \mathrm{m}^{2}\right)$ & $26.9(5.2)$ & $27.5(5.2)$ & $27.8(5.0)$ \\
\hline
\end{tabular}

${ }^{*}$ Data are mean (SD) unless specified otherwise.

$\dagger \mathrm{N}=246$. Thirty-seven participants did not come back to follow-up; 11 in placebo, 16 in the $10 \mu \mathrm{g}$ group, and 10 in the $25 \mu \mathrm{g}$ group. The baseline characteristics of these were not different from those who completed the study.

BMI, body mass index; HbA1c, glycated hemoglobin; HDL, high-density lipoprotein; LDL, low-density lipoprotein; S-25(OH)D, serum 25-hydroxyvitamin D. 
Table 2 Effect of vitamin D supplementation* on markers of glucose metabolism, serum lipids, and body mass index

\begin{tabular}{|c|c|c|c|c|c|}
\hline & Baseline‡ & After 16 weeks $¥$ & $\begin{array}{l}\text { Change from } \\
\text { baseline to } 16 \text { weeks } ¥\end{array}$ & $\begin{array}{l}\text { Difference }(95 \% \mathrm{Cl}) \\
\text { compared to placebot }\end{array}$ & p Value \\
\hline \multicolumn{6}{|l|}{ S-25(OHD) (nmol/L) } \\
\hline Intervention $(n=143)$ & $28.7(18.6)$ & $48.8(19.6)$ & $20.1(21.7)$ & \multirow[t]{2}{*}{21.3 (16.7 to 26.0$)$} & \multirow[t]{2}{*}{$<0.0001$} \\
\hline Placebo $(n=71)$ & $29.2(15.6)$ & $27.5(13.7)$ & $-1.5(11.3)$ & & \\
\hline \multicolumn{6}{|l|}{$\mathrm{HbA1c}(\%) \S$} \\
\hline Intervention $(n=139)$ & $5.65(0.6)$ & $5.68(0.7)$ & $0.03(0.17)$ & \multirow[t]{2}{*}{$0.01(-0.04$ to 0.06$)$} & \multirow[t]{2}{*}{0.7} \\
\hline Placebo $(n=70)$ & $5.52(0.4)$ & $5.52(0.5)$ & $0.01(0.18)$ & & \\
\hline \multicolumn{6}{|l|}{ S-fructosamine ( $\mu \mathrm{mol} / \mathrm{L})$} \\
\hline Intervention $(n=143)$ & $251(45.9)$ & $249.5(58.4)$ & $-1.1(27.6)$ & \multirow[t]{2}{*}{$1.7(-5.3$ to 8.7$)$} & \multirow[t]{2}{*}{0.6} \\
\hline Placebo $(n=71)$ & $245(30.8)$ & $242.8(29.9)$ & $-3.2(16.5)$ & & \\
\hline \multicolumn{6}{|c|}{ Total cholesterol (mmol/L) } \\
\hline Intervention $(n=143)$ & $4.9(0.8)$ & $4.8(0.8)$ & $-0.1(0.5)$ & \multirow[t]{2}{*}{$-0.03(-0.17$ to 0.12$)$} & \multirow[t]{2}{*}{0.7} \\
\hline Placebo $(n=71)$ & $4.9(0.9)$ & $4.8(0.8)$ & $-0.1(0.5)$ & & \\
\hline \multicolumn{6}{|l|}{ LDL-cholesterol (mmol/L) } \\
\hline Intervention $(n=143)$ & $3.3(0.8)$ & $3.2(0.8)$ & $-0.06(0.4)$ & \multirow[t]{2}{*}{$-0.01(-0.1$ to 0.1$)$} & \multirow[t]{2}{*}{0.9} \\
\hline Placebo $(n=71)$ & $3.3(0.8)$ & $3.3(0.8)$ & $-0.05(0.5)$ & & \\
\hline \multicolumn{6}{|c|}{ HDL-cholesterol (mmol/L) } \\
\hline Intervention $(n=143)$ & $1.4(0.3)$ & $1.37(0.3)$ & $-0.01(0.2)$ & \multirow[t]{2}{*}{$-0.002(-0.05$ to 0.05$)$} & \multirow[t]{2}{*}{0.9} \\
\hline Placebo $(n=71)$ & $1.4(0.3)$ & $1.39(0.3)$ & $-0.02(0.2)$ & & \\
\hline \multicolumn{6}{|l|}{ Triglycerides (mmol/L) } \\
\hline Intervention $(n=143)$ & $1.6(1.1)$ & $1.4(0.8)$ & $-0.18(0.9)$ & \multirow[t]{2}{*}{$0.03(-0.2$ to 0.20$)$} & \multirow[t]{2}{*}{0.7} \\
\hline Placebo $(n=71)$ & $1.5(1.1)$ & $1.3(0.7)$ & $-0.16(0.9)$ & & \\
\hline \multicolumn{6}{|l|}{$\operatorname{BMI}\left(\mathrm{kg} / \mathrm{m}^{2}\right)$} \\
\hline Intervention $(n=143)$ & $26.9(4.9)$ & $26.9(5.1)$ & $-0.03(0.6)$ & \multirow[t]{2}{*}{$-0.05(-0.2$ to 0.1$)$} & \multirow[t]{2}{*}{0.6} \\
\hline Placebo $(n=71)$ & $28.1(5.2)$ & $28.1(5.2)$ & $0.02(0.7)$ & & \\
\hline \multicolumn{6}{|c|}{$\begin{array}{l}{ }^{*} \text { Combined } 10 \text { and } 25 \mu \mathrm{g} \text { doses of vitamin } \mathrm{D} \text {. } \\
\text { †Adjusted for baseline values. } \\
\text { †Data are mean (SD) unless specified otherwise. } \\
\S \mathrm{N}=209 \text {. Five participants had insufficient amount of blood for } \mathrm{HbA} 1 \mathrm{c} \text { measurements. The mean age of these was } 32 \text { years and the s-25(OH)D } \\
\text { was } 36.4 \mathrm{nmol} / \mathrm{L}(16.7) \text {, three persons were in the } 10 \mu \mathrm{g} \text { group while the others were in the two other groups each. } \\
\text { BMl, body mass index; HbA1c, glycated hemoglobin; HDL, high-density lipoprotein; LDL, low-density lipoprotein; } \mathrm{S}-25(\mathrm{OH}) \mathrm{D}, \mathrm{serum} \\
\text { 25-hydroxyvitamin D. }\end{array}$} \\
\hline
\end{tabular}

\section{Effect of supplementation on vitamin D status}

S-25 $(\mathrm{OH}) \mathrm{D}$ increased from a mean of approximately $29 \mathrm{nmol} / \mathrm{L}$ at baseline to $49 \mathrm{nmol} / \mathrm{L}$ after intervention, with little change in the placebo group (table 2).

\section{Effect of supplementation on end point measures}

A 16-week supplementation with vitamin $\mathrm{D}_{3}$ (10 or $25 \mu \mathrm{g}$ combined compared) to placebo had no significant effect on HbAlc, fructosamine, total cholesterol, LDL, HDL, and triglycerides or BMI (table 2).

\section{Subgroup analyses}

There were no significant effects on outcome variables in subgroups defined by baseline values (figure 2). There were also no significant effects of $25 \mu \mathrm{g}$ vitamin D versus placebo on any of the end points (data not shown).

Furthermore, there were no significant differences between the combined intervention groups and placebo in any of the end points after stratification by baseline concentration of s-25 $(\mathrm{OH}) \mathrm{D}$ higher or lower than $25 \mathrm{nmol} / \mathrm{L}$, or after stratification by gender (data not shown).
Subgroups (by baseline levels): $\mathrm{HbA} 1 \mathrm{c}<5.7 \%(\mathrm{n}=81)$ $\mathrm{HbA} 1 \mathrm{c} \geq 5.7 \%(n=128)$

Fructosamine $<0.25 \mathrm{mmol} / \mathrm{l}(\mathrm{n}=101)$ Fructosamine $\geq 0.25 \mathrm{mmol} / \mathrm{l}(\mathrm{n}=113)$

LDL-cholesterol $<3.3 \mathrm{mmol} / \mathrm{l}(\mathrm{n}=102)$ LDL-cholesterol $\geq 3.3 \mathrm{mmol} / \mathrm{l}(\mathrm{n}=112)$

$\mathrm{HDL}$-cholesterol $<1.4 \mathrm{mmol} / \mathrm{l}(\mathrm{n}=106)$ $\mathrm{HDL}$-cholesterol $\geq 1.4 \mathrm{mmol} / \mathrm{l}(\mathrm{n}=108)$

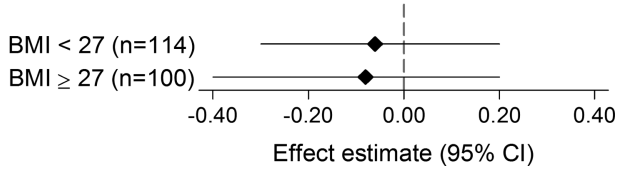

Figure 2 Subgroup analysis. Effect of vitamin D supplementation on outcome variables in subgroups defined by baseline levels of the respective outcome variables. Effect estimates for each outcome variable are difference in change from baseline to 16 weeks between the combined intervention groups (10 or $25 \mu \mathrm{g}$ ) and the placebo group. Within each subgroup, the effect estimate was adjusted for the baseline level of the respective outcome variables (baseline value entered as a continuous variable in the regression model). 
DISCUSSION

Principal findings

In this study, we found that a 16-week supplementation with either 10 or $25 \mu \mathrm{g}$ vitamin $\mathrm{D}_{3}$ daily to healthy immigrants from South Asia, the Middle East, or Africa and now living in Norway did not significantly affect HbAlc, fructosamine, serum lipids, or BMI. Notably, the $95 \%$ CI for mean difference in HbA1c $(-0.04$ to 0.06$)$ excluded $-0.5 \%$, which was our a priori defined smallest difference of clinical relevance. We can therefore reasonably exclude large effects on HbA1c of a 16-week intervention with these dosages.

\section{Strengths and weaknesses}

The study was a strictly performed double-blinded, randomized, placebo-controlled trial with good compliance and relatively high retention. According to our prestudy power calculation, our relatively large sample size should provide good statistical power to detect even small-to-moderate effects on HbA1c. Blood samples were assayed in one batch. In addition to the commonly measured HbAlc, we also included fructosamine, which refers to glycated serum proteins and reflects the average blood glucose levels for the previous 2-3 weeks. We reasoned that this would increase the chance of detecting changes during a 16-week intervention period. The ethnic minorities targeted in our study are known to have a generally poor vitamin D status and relatively high risk of type 2 diabetes and other cardiovascular risk factors, as confirmed in our study. ${ }^{1619} 20$ The study also has some limitations. It was designed primarily for muscular strength outcomes, but HbAlc was an important prespecified outcome described in the protocol. We did not measure fasting glucose levels and insulin sensitivity, which would have been more demanding for the participants with possibly negative effects on recruitment and participation of the study participants. Also, the participants may not have been exposed for a sufficiently long time to high levels of circulating s-25 $(\mathrm{OH}) \mathrm{D}$ to affect some of our outcome variables.

\section{Findings in relation to other studies}

A recently published systematic review and meta-analysis concluded that currently there is insufficient evidence to recommend vitamin $\mathrm{D}$ supplementation in order to improve glycemia or insulin resistance in patients with diabetes, normal fasting glucose, or impaired glucose tolerance. ${ }^{21}$ In the systematic review, only four studies examined HbAlc as an outcome, and all were done in participants with diabetes or another serious chronic disease, or the intervention was done with 1-hydroxyvitamin D, which circumvents the strictly controlled hydroxylation of the 1-position (normally of $25(\mathrm{OH}) \mathrm{D})$.

A few other relevant studies including healthy participants with low vitamin D status have been published after the systematic review cited above. Studies with similar characteristics as ours, with a duration of 3-
12 months, consistently did not show clear effects on HbAlc (see online electronic supplementary material for details), and generally supported our result. For instance, Davidson et $a l^{22}$ examined healthy persons from ethnic minorities in the USA (Latinos and African-Americans) with $\mathrm{HbAlc}>5.8 \%$ and s-25 $(\mathrm{OH}) \mathrm{D}$ $<75 \mathrm{nmol} / \mathrm{L}$ at baseline. They showed no effect of high doses of vitamin D supplementation (doses corresponding to $>200 \mu \mathrm{g} /$ day) for 1 year on various measures of glycemia or insulin sensitivity. HbAlc was slightly reduced in those receiving vitamin $\mathrm{D}$, but the effect size was deemed clinically non-relevant. While we did not restrict participants by baseline s-25(OH)D or HbAlc, the large majority of our participants in our study had levels $<50 \mathrm{nmol} / \mathrm{L}$ and many had HbA1c $>5.7 \%$. Harris et $a l^{23}$ gave a 3-month supplementation with $4000 \mathrm{IU}$ $(100 \mu \mathrm{g}) \quad$ vitamin $\quad \mathrm{D}_{3}$ daily in overweight African-Americans with prediabetes but found no effect on HbAlc or other measures of glycemia. A RCT by Mitri et $a l^{24}$ examining the effect of vitamin D supplementation in adults at high risk of diabetes concluded that short-term supplementation with cholecalciferol did not have a significant effect on HbAlc.

In two other relatively large studies performed in the North of Norway, capsules of $20000 \mathrm{IU}(500 \mu \mathrm{g})$ vitamin $\mathrm{D}_{3}$ or placebo were given twice weekly for 6 months to healthy Norwegians with s-25(OH)D levels $<50 \mathrm{nmol} / \mathrm{L}$, but the intervention did not improve HbAlc. ${ }^{25}$ We did not identify any other randomized studies of the effect of vitamin $\mathrm{D}$ on fructosamine. The lack of effect on fructosamine is nevertheless consistent with the lack of effect on HbAlc and on fasting glucose seen in other studies $^{21}$ since fructosamine also reflects aspects of glucose metabolism.

Results from systematic reviews of RCTs of vitamin D on lipids show a lack of effect of vitamin D on total cholesterol, LDL-cholesterol, and HDL-cholesterol which was clearly consistent with our study. ${ }^{1326}$ Also, our updated meta-analysis of recent trials similar to ours supported the lack of effect of vitamin D on serum total cholesterol in healthy adults (confer electronic supplementary material). A consistent lack of effect of vitamin D on serum lipids was also found in a 12-month study among Pakistani immigrants in Copenhagen, Denmark. ${ }^{27}$

A recently conducted review of RCTs on either vitamin $\mathrm{D}$ plus calcium or only vitamin $\mathrm{D}$, and reporting effects on adiposity outcomes including BMI, concluded that current evidence from RCTs did not consistently support the contention that calcium and vitamin D accelerated weight or fat loss in obesity. ${ }^{28}$ Also, von Hurst et al conducted a randomized controlled study in 81 women of South Asian origin living in New Zealand and aged 23-68 years to 6 months of supplementation with $100 \mu \mathrm{g} /$ day of vitamin D or placebo and stated that there was no significant effect on BMI. In accordance with other RCTs, we did not find any effect of vitamin D supplementation on BMI. ${ }^{29}{ }^{30}$ Our updated meta-analysis on BMI clearly showed that there was no 
indication on an effect of vitamin D on BMI in healthy adults (see online electronic supplementary material).

In our study, both doses of vitamin $\mathrm{D}$ supplementation were sufficient to raise s-25 $(\mathrm{OH}) \mathrm{D}$ concentration significantly compared with the placebo group, but $\geq 50 \mathrm{nmol} / \mathrm{L}$ was not reached in $43 \%$ (25 $\mu \mathrm{g}$ supplementation group) and $62 \%$ (10 $\mu$ g supplementation group).

The existing literature on the effect of vitamin $\mathrm{D}$ on the end points included in our study did not identify any effects even when higher doses (even above $100 \mu \mathrm{g}$ / day) and longer duration (up to 12 months) of treatment with vitamin $\mathrm{D}$ were used. Thus, we believe that the lack of effect in our study would not change with another regime of vitamin $\mathrm{D}$ treatment.

In conclusion, in healthy adults with an immigrant background low in vitamin $\mathrm{D}$, supplementation with vitamin $\mathrm{D}_{3}$ during 16 weeks did not improve HbA1c, fructosamine, lipid profiles, and BMI. Our literature review and updated meta-analysis showed that the lack of effect of vitamin $\mathrm{D}$ on these end points in healthy adults was consistent and corroborated by other similar studies.

\section{Future research}

Over $1 / 3$ of the study participants had prediabetes HbA1c levels and are at risk of development of diabetes; therefore, exploring effective preventive means for vitamin $\mathrm{D}$ deficiency, diabetes, and cardiovascular disease is urgently needed. Also, more work is needed to study the long-term health consequences of the low vitamin $\mathrm{D}$ status of immigrants.

\section{Author affiliations}

${ }^{1}$ Department of Community Medicine, Institute of Health and Society, University of Oslo, Oslo, Norway

${ }^{2}$ Department of General Practice, Institute of Health and Society, University of Oslo, Oslo, Norway

${ }^{3}$ Division of Epidemiology, Norwegian Institute of Public Health, Oslo, Norway

Acknowledgements The authors express their gratitude to all study participants. Thanks to all those organizations, such as KIA center, and other centers which allowed us to use their venues for recruitment and data collection. Thanks to Marie Buchmann and Anne-Lise Sund at the Fürst Medical Laboratory for their invaluable assistance and expert advice on blood collection and analysis, Eva Kristensen for her assistance with data collection, Ingvild Dalen and Magne Thoresen for statistical consultation. Finally, thanks to Anne Karen Jenum for the biobank support.

Contributors AAM and KVK designed the study protocol and conducted and collected the data. LCS conducted a literature search, summary of the literature, and updated the meta-analysis with input from AAM, KVK, and HEM. AAM carried out the analysis and drafted the manuscript. KVK, LCS, HEM, MB, and PL contributed to the planning and design of the study and the interpretation of data, as well as a critical revision of the manuscript. All authors approved the final manuscript to be submitted. AAM and HEM are the guarantors of this work and, as such, had full access to all of the data in the study and take responsibility for the integrity of the data and the accuracy of the data analysis.

Funding This research was funded by the Norwegian Women's Public Health Association and University of Oslo. The study was also supported by the Fürst Medical Laboratory and by Nycomed Pharma AS, which included free trial drugs.

\section{Competing interests None.}

Ethics approval The study was approved by the Regional Committee for Medical and Health Research Ethics (study code: 2010/1982).

Provenance and peer review Not commissioned; externally peer reviewed.

Data sharing statement No additional data are available.

Open Access This is an Open Access article distributed in accordance with the Creative Commons Attribution Non Commercial (CC BY-NC 3.0) license, which permits others to distribute, remix, adapt, build upon this work noncommercially, and license their derivative works on different terms, provided the original work is properly cited and the use is non-commercial. See: http:// creativecommons.org/licenses/by-nc/3.0/

\section{REFERENCES}

1. Madar AA, Stene LC, Meyer HE. Vitamin D status among immigrant mothers from Pakistan, Turkey and Somalia and their infants attending child health clinics in Norway. Br J Nutr 2009;101:1052-8.

2. Holvik K, Meyer HE, Haug E, et al. Prevalence and predictors of vitamin D deficiency in five immigrant groups living in Oslo, Norway: the Oslo Immigrant Health Study. Eur J Clin Nutr 2005;59:57-63.

3. Andersen R, Molgaard C, Skovgaard LT, et al. Pakistani immigrant children and adults in Denmark have severely low vitamin D status. Eur J Clin Nutr 2008;62:625-34.

4. Lips P. Vitamin D status and nutrition in Europe and Asia. J Steroid Biochem Mol Biol 2007;103:620-5.

5. Bouillon R, Carmeliet G, Verlinden L, et al. Vitamin D and human health: lessons from vitamin D receptor null mice. Endocr Rev 2008;29:726-76.

6. Jenum AK, Diep LM, Holmboe-Ottesen G, et al. Diabetes susceptibility in ethnic minority groups from Turkey, Vietnam, Sri Lanka and Pakistan compared with Norwegians-the association with adiposity is strongest for ethnic minority women. BMC Public Health 2012;12:150.

7. Wandell PE, Carlsson A, Steiner KH. Prevalence of diabetes among immigrants in the Nordic countries. Curr Diabetes Rev 2010;6:126-33.

8. Barnett AH, Dixon AN, Bellary S, et al. Type 2 diabetes and cardiovascular risk in the UK south Asian community. Diabetologia 2006;49:2234-46

9. Tran AT, Straand J, Diep LM, et al. Cardiovascular disease by diabetes status in five ethnic minority groups compared to ethnic Norwegians. BMC Public Health 2011;11:554.

10. Gholap N, Davies M, Patel K, et al. Type 2 diabetes and cardiovascular disease in South Asians. Prim Care Diabetes 2011;5:45-56.

11. Pittas AG, Nelson J, Mitri J, et al. Plasma 25-hydroxyvitamin D and progression to diabetes in patients at risk for diabetes: an ancillary analysis in the Diabetes Prevention Program. Diabetes Care 2012;35:565-73.

12. Hutchinson MS, Figenschau Y, Njolstad I, et al. Serum 25-hydroxyvitamin $D$ levels are inversely associated with glycated haemoglobin $(\mathrm{HbA}(1 \mathrm{c}))$. The Tromso Study. Scand J Clin Lab Invest 2011;71:399-406.

13. Jorde R, Grimnes G. Vitamin D and metabolic health with special reference to the effect of vitamin D on serum lipids. Prog Lipid Res 2011;50:303-12.

14. Wang TJ, Pencina MJ, Booth SL, et al. Vitamin D deficiency and risk of cardiovascular disease. Circulation 2008;117:503-11.

15. Knutsen KV, Madar AA, Lagerlov $P$, et al. Does vitamin D improve muscle strength in adults? A randomized, double-blind, placebo-controlled trial among ethnic minorities in Norway. J Clin Endocrinol Metab 2014;99:194-202.

16. Nathan DM, Kuenen J, Borg R, et al. Translating the A1C assay into estimated average glucose values. Diabetes Care 2008;31:1473-8.

17. Wright LAC, Hirsch IB. The Challenge of the use of glycemic biomarkers in diabetes: reflecting on hemoglobin A1C, 1,5-anhydroglucitol, and the glycated proteins fructosamine and glycated albumin. Diabetes Spectr 2012;25:141-8.

18. Jorde R, Figenschau Y. Supplementation with cholecalciferol does not improve glycaemic control in diabetic subjects with normal serum 25-hydroxyvitamin D levels. Eur J Nutr 2009;48:349-54.

19. Hjellset VT, Bjorge B, Eriksen HR, et al. Risk factors for type 2 diabetes among female Pakistani immigrants: the InvaDiab-DEPLAN study on Pakistani immigrant women living in Oslo, Norway. $J$ Immigr Minor Health 2011;13:101-10. 
20. Knutsen KV, Brekke M, Gjelstad S, et al. Vitamin D status in patients with musculoskeletal pain, fatigue and headache: a cross-sectional descriptive study in a multi-ethnic general practice in Norway. Scand $J$ Prim Health Care 2010;28:166-71.

21. George PS, Pearson ER, Witham MD. Effect of vitamin D supplementation on glycaemic control and insulin resistance: a systematic review and meta-analysis. Diabet Med 2012;29: e142-50.

22. Davidson MB, Duran P, Lee ML, et al. High-dose vitamin d supplementation in people with prediabetes and hypovitaminosis $\mathrm{d}$. Diabetes Care 2013;36:260-6.

23. Harris SS, Pittas AG, Palermo NJ. A randomized, placebo-controlled trial of vitamin D supplementation to improve glycaemia in overweight and obese African Americans. Diabetes Obes Metab 2012;14:789-94.

24. Mitri J, Dawson-Hughes B, Hu FB, et al. Effects of vitamin D and calcium supplementation on pancreatic beta cell function, insulin sensitivity, and glycemia in adults at high risk of diabetes: the Calcium and Vitamin D for Diabetes Mellitus (CaDDM) randomized controlled trial. Am J Clin Nutr 2011;94:486-94.
25. Jorde R, Strand Hutchinson M, Kjaergaard M, et al.

Supplementation with high doses of vitamin $D$ to subjects without vitamin $\mathrm{D}$ deficiency may have negative effects: pooled data from four intervention trials in Tromso. ISRN Endocrinol 2013;2013:348705.

26. Elamin MB, Abu Elnour NO, Elamin KB, et al. Vitamin D and cardiovascular outcomes: a systematic review and meta-analysis. $J$ Clin Endocrinol Metab 2011;96:1931-42.

27. Andersen R, Brot C, Mejborn $\mathrm{H}$, et al. Vitamin D supplementation does not affect serum lipids and lipoproteins in Pakistani immigrants. Eur J Clin Nutr 2009;63:1150-3.

28. Soares MJ, Chan She Ping-Delfos W, Ghanbari MH. Calcium and vitamin $D$ for obesity: a review of randomized controlled trials. Eur $J$ Clin Nutr 2011;65:994-1004.

29. Wamberg L, Kampmann U, Stodkilde-Jorgensen $\mathrm{H}$, et al. Effects of vitamin $\mathrm{D}$ supplementation on body fat accumulation, inflammation, and metabolic risk factors in obese adults with low vitamin $D$ levels -results from a randomized trial. Eur J Intern Med 2013;24:644-9.

30. Sneve M, Figenschau Y, Jorde R. Supplementation with cholecalciferol does not result in weight reduction in overweight and obese subjects. Eur J Endocrinol 2008;159:675-84. 